NASA Technical Memorandum 106956

\title{
Heat Transfer Predictions for Two Turbine Nozzle Geometries at High Reynolds and Mach Numbers
}

R.J. Boyle

Lewis Research Center

Cleveland, Ohio

and

R. Jackson

DRA Pyestock

Farnbourough, Hants, England

Prepared for the

40th Gas Turbine and Aeroengine Congress and Exposition sponsored by the American Society of Mechanical Engineers Houston, Texas, June 5-8, 1995

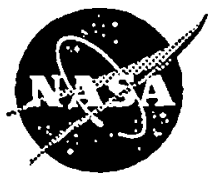

National Aeronautics and Space Administration

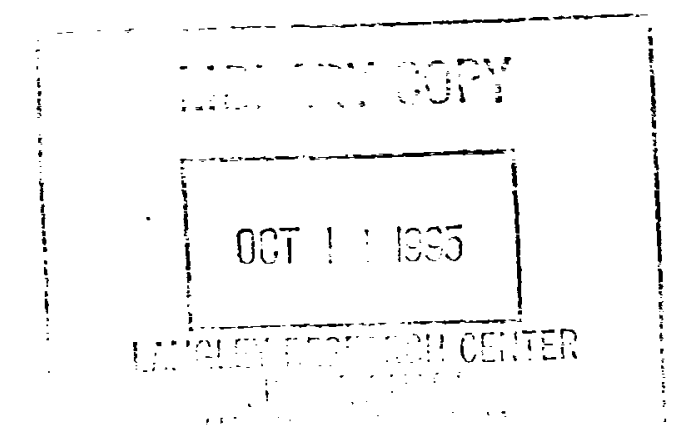




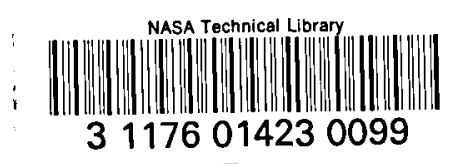

\title{
HEAT TRANSFER PREDICTIONS FOR TWO TURBINE NOZZLE GEOMETRIES AT HIGH REYNOLDS AND MACH NUMBERS
}

\author{
R. J. Boyle \\ NASA Lewis Research Center \\ Cleveland, OH 44135 \\ R. Jackson \\ DRA Pyestock \\ Farnbourough, Hants, England
}

\begin{abstract}
Predictions of turbine vane and endwall heat transfer and pressure distributions are compared with experimental measurements for two vane geometries. The differences in geometries were due to differences in the hub profile, and both geometries were derived from the design of a high rim speed turbine(HRST). The experiments were conducted in the Isentropic Light Piston Facility(ILPF) at Pyestock at a Reynolds No. of $5.3 \times 10^{6}$, a Mach No. of 1.2 , and a wall-to-gas temperature ratio of 0.66 . Predictions are given for two different steady state three-dimensional Navier-Stokes computational analyses. C-type meshes were used, and algebraic models were employed to calculate the turbulent eddy viscosity. The effects of different turbulence modeling assumptions on the predicted results are examined. Comparisons are also given between predicted and measured total pressure distributions behind the vane. The combination of realistic engine geometries and flow conditions proved to be quite demanding in terms of the convergence of the CFD solutions. An appropriate method of grid generation, which resulted in consistently converged CFD solutions, was identified.

\begin{tabular}{|c|c|}
\hline & Nomenclature \\
\hline$c$ & - True chord \\
\hline$c_{x}$ & - Axial chord \\
\hline$d$ & - Distance from surface \\
\hline $\boldsymbol{k}$ & - Thermal conductivity \\
\hline$M_{\text {IS }}$ & - Isentropic Mach No. \\
\hline$N u$ & - Nusselt No. based on true chord and $k(T$ \\
\hline$P^{\prime}$ & - Total pressure \\
\hline $\operatorname{Pr}$ & - Prandlt No. \\
\hline
\end{tabular}
\end{abstract}

$\begin{array}{ll}P r_{t} & - \text { Turbulent Prandlt No. } \\ R e_{2} & - \text { Exit true chord Reynolds No. } \\ s & - \text { Surface distance } \\ T^{\prime} & - \text { Total temperature } \\ T u & - \text { Turbulence intensity } \\ U & - \text { Velocity } \\ y_{1}^{+} & - \text {Normalized distance of first grid line } \\ \theta & - \text { Momentum thickness } \\ \mu_{t} & - \text { Turbulent eddy viscosity } \\ \rho & - \text { Density } \\ \text { Subscripts } & \\ \text { EXIT } & - \text { Exit of computational domain } \\ \text { INLET } & - \text { Inlet of computational domain } \\ \text { M } & - \text { Measurement plane } \\ \text { S } & - \text { Surface of blade } \\ 1 & - \text { inlet, or surface } \\ 2 & - \text { outlet, or surface }\end{array}$

\section{INTRODUCTION}

Confidence in the validity of three-dimensional Navier-Stokes predictions for turbine aerodynamic performance and surface heat transfer characteristics increases when computations are shown to predict measured values for cases which approach actual engine geometry and flow conditions. For example, the engine Reynolds and Mach numbers, as well as the turbulence intensity should be matched as closely as possible. Confidence levels increase when the test geometry incorporates features which are part of a three-dimensional design philosophy. A turbine vane design philosophy could include convergence in the meridional plane, as well as underturning of the vane in the endwall region to reduce secondary losses. When design considerations 
such as these are present, blade and endwall heat transfer may be substantially different from values measured in either a linear or annular cascade with constant section vane geometry.

Comparisons with experimental turbine blade heat transfer data which include both endwall and blade results provide a significant test of three-dimensional Navier-Stokes analyses, since the endwall heat transfer is significantly affected by secondary flow patterns. The blade heat transfer is more two dimensional in nature. Blair(1974), and Boyle and Russell(1990) presented endwall heat transfer distributions obtained in linear cascades for large scale vanes, at relatively low Mach numbers. York et al. (1984) obtained similar data, but at transonic Mach numbers. Arts and Beider(1994) presented vane and endwall heat transfer measurements obtained at transonic Mach numbers in an annular cascade with constant radii. endwalls.

Test cases with hubs and shrouds of constant radii, and with blades of little or no twist provide useful information for predicting aerodynamic and heat transfer behavior. However, turbine blading employed in actual engines typically has vanes with significant endwall convergence and twisted blades. Comparing predictions for test cases with these geometric features increases confidence in the analysis' ability to predict aerodynamic and heat transfer performance at actual engine conditions. The previously cited experimental data are for geometries with constant radii hub and shroud surfaces, and with little or no blade twist. A series of experiments measuring turbine aerodynamics and surface heat transfer utilizing a vane geometry representative of an actual engine have been conducted in the DRA Isentropic Light Piston Facility(ILPF). Kingcombe, Harasagama, Leversuch, and Wedlake(1989), presented the overall performance and detailed vane heat transfer and aerodynamic measurements for a transonic turbine. Vane measurements were given for a range of Reynolds numbers at an exit Mach number of 1.14. Harasagama and Wedlake(1991) presented experimental surface pressure and heat transfer distributions on the vane and on the hub and casing endwalls for a range of Reynolds and Mach numbers. Both of these references were for a vane with reduced turning at the hub and tip casing, but with constant radius endwalls. Chana(1992), measured vane, hub, and tip heat transfer and pressure distributions using the same vane geometry for two different hub contour geometries.

In recent years a number of three-dimensional Navier-Stokes predictions for vane and/or rotor heat transfer have been presented. Choi and Knight(1988), Hah(1989), and Ameri and Arnone(1994) showed com- parisons with large scale-low speed heat transfer data of Graziani et al.(1980) using both algebraic and two equation turbulence models. Chima et al.(1993) developed an algebraic turbulence model, which was used to compare vane endwall heat transfer predictions over a range of Reynolds numbers with the experimental data of Boyle and Russell(1990). In addition to predictions for isolated blade rows, three-dimensional NavierStokes heat transfer analyses have been performed for entire turbine stages. Boyle and Giel(1992), and Ameri and Arnone(1992) showed comparisons with the experimental heat transfer data of Dunn et al.(1994) and Blair(1994). Heider and Arts(1994) showed comparisons of predicted heat transfer with the data of Arts and Heider(1994) using the Baldwin-Lomax turbulence model. Except for the comparisons of Heider and Arts(1994), these comparisons have been for subsonic conditions. It remains to be seen if algebraic models can predict turbine heat transfer as accurately as two equation models for high Mach and Reynolds number cases.

The ideal turbulence model would give accurate heat transfer predictions with little computational overhead. Algebraic turbulence models require less computational effort compared to multiple equation models. They also have the advantage in that empirical correlations can be easily incorporated into the modeling to account for effects such as transition and augmentation of the leading edge heat transfer due to freestream turbulence. However, if the algebraic models are not accurate, their use is not warranted. Ameri and Arnone(1994) showed heat transfer predictions using algebraic and two-equation models. Their results indicated that the degree of agreement with the experimental data was not significantly improved using a two-equation turbulence model. Results using either turbulence model were in good agreement with the experimental data. Other factors, such as the thermal boundary condition and spanwise grid density, resulted in heat transfer variations as large as between the two turbulence models. Algebraic models also require less CPU time per time step, and less core memory than higher order models. Ameri and Arnone(1994), showed that heat transfer predictions using two-equation models required nearly twice the CPU time to converge, compared with an algebraic model solution. The high Reynolds number cases investigated herein require large size grids, which favors algebraic models. Also, use of higher order models would have required additional computer simulations to determine the effects of the assumed value of the inlet length scale on the predicted heat transfer. The length scale at the inlet was not 
known, and Ameri and Arnone(1992) showed that blade surface heat transfer is significantly affected by the assumed value for the length scale at the inlet boundary.

As the result of a cooperative agreement between NASA Lewis Research Center and the Defence Research Agency(DRA, Pyestock) a study was undertaken to predict the turbine vane heat transfer of two geometric configurations. The predictions are compared with the experimental measurements of Chana(1992). These measurements included pressure and heat transfer distributions on the vane surfaces as well as the hub and tip casings. Pressure and heat transfer distributions were measured on the vane, hub, and shroud surfaces for two different hub endwall geometries. In addition, the total pressure distribution behind the vane was measured for one configuration. These data are for a high Reynolds number of $R e_{2}=5.3 \times 10^{6}$, and at a pressure ratio corresponding to an exit Mach number of 1.2. The high Reynolds number requires small grid spacing in the near wall region. This, in turn, results in large computational grids. Because of the large computational grids, and indications that algebraic turbulence models would give accurate heat transfer predictions, algebraic turbulence models were used. Heat transfer comparisons are shown using three different models for turbulent eddy viscosity. Predictions were made for the vane surface, hub, and casing heat transfer. Also, the ability of the analyses to predict surface static pressures, and the total pressure distribution behind the vane is examined. The reason for comparing predicted wake profiles with measurements is that these comparisons may shed light on the differences in the heat transfer results. Good agreement in the downstream pressure distributions indicates that the analysis predicted secondary flows correctly.

\section{DESCRIPTION OF COMPUTATIONAL ANALYSIS}

Two different steady state three-dimensional Navier-Stokes computer code analyses were used. One computer code, referred to as TRAF3D, is the finite volume analysis described by Arnone et al.(1992), The other code, referred to as RVC3D, is the finite difference analysis described by Chima(1991) and by Chima and Yokota(1988). The reason for using two Navier-Stokes analyses is to help insure that the conclusions drawn from this work are applicable to a range of CFD analyses, and that they are not specific to any one formulation. While the two Navier-Stokes analyses had different approaches to the discretization, they were similar in other respects. Both analyses used a Runge-Kutta scheme to march the solution in time, and both employed implicit residual smoothing.

The code TRAF3D uses the turbulence model developed by Baldwin and Lomax(1978). The RVC3D code uses either of two turbulence models. One is a variation of the Baldwin-Lomax model, and results obtained using this model are labeled as Chima's model. The other is a variation of the Cebeci-Smith(1974) model, and results obtained using this model are labeled as Cebeci-Smith results. Chima et al.(1993) discuss the implementation of these two models. Unless stated otherwise references to the TRAF3D code imply the Baldwin-Lomax turbulence model, and references to the RVC3D code imply Chima's turbulence model. Both of these models use the Baldwin-Lomax transition criterion. The transition criterion in the Baldwin-Lomax model does not account for the effects of freestream turbulence. Since these tests, and actual engine operation, are at relatively high levels of turbulence, the transition criterion of Mayle(1991) was incorporated into the turbulence model. Also, high freestream turbulence results in leading edge Frossling numbers significantly greater than unity. The model of Smith and Kuethe(1966) was used to account for the effects of freestream turbulence. $P r$ and $P r_{t}$ were held constant at 0.70 and 0.90 respectively.

The inlet total pressure was 5.0 bars. The inlet total temperature was $440^{\circ} \mathrm{K}$, and the surface temperature was $290^{\circ} \mathrm{K}$. The hub static-to-total pressure ratio was 0.42 . The Reynolds number based on exit conditions, and true chord was $5.3 \times 10^{6}$. A uniform temperature boundary condition was imposed on all solid boundaries. Spanwise radial equilibrium was assumed at the exit boundary of the calculation domain. At each spanwise location the exit static pressure was allowed to vary in the circumferential direction. The average static pressure was specified at the hub exit, but the pitchwise variation was determined from the internal flow field. The hub and tip inlet full boundary layer thicknesses were determined from measurements to be $9 \%$ of axial chord. Uniform total conditions were specified for the inlet core flow, and uniform static pressures were specified through the inlet boundary layers. The inlet temperature and velocity profiles through the boundary layers were determined using flat plate correlations. The friction factor and Stanton number are first determined from the specified inlet boundary layer thickness. Once these quantities are found, the profiles are determined from correlations given by Kays and Crawford(1980). Using a simple power law for the inlet temperature profile produces an erroneous result, since the power law gives an infinite gradient at the wall. 


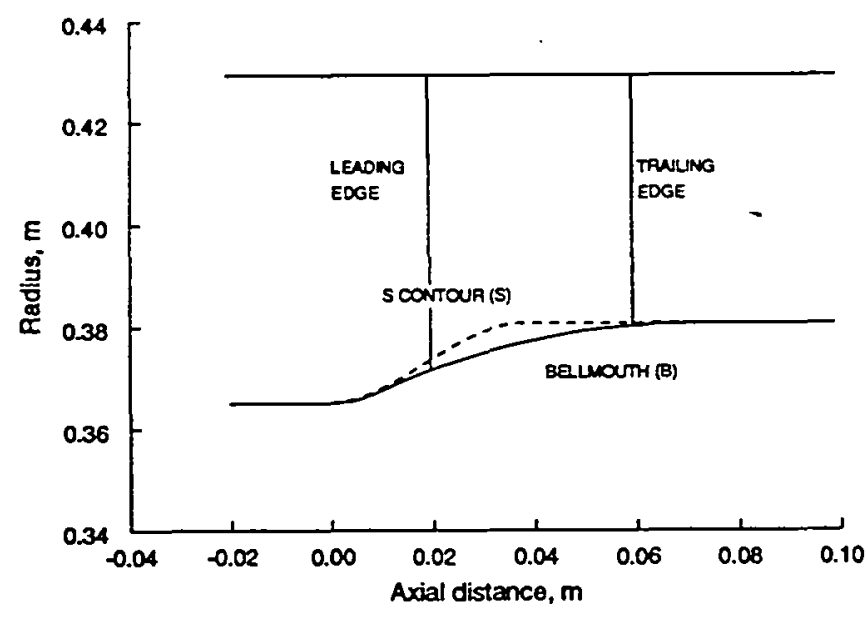

Fig. 1a Meridional view of vane configuration.

The primary convergence criterion was to examine the solution to see that the variables of interest were not changing with increased iterations. The primary variable of interest was surface heat transfer, because it converged at a slower rate than surface pressures. Because of the large CPU requirements, most cases were not started from a simple initial flow field, but, when a parameter was changed, the previous solution was used as an initial guess. If the new parameter value produced a small change in the flow field, the residuals did not necessarily increase significantly initially. With this approach, relying on "orders of maginitude" decreases in residuals was impractical. Low residuals relative to initial values without restart were verified, but were not the primary convergence measure. The inlet and exit mass flows differed by less than $1 \%$ at convergence.

\section{DISCUSSION of RESULTS}

Figure la shows a meridional view of the two configurations. They differ in the shape of the hub. For presentation purposes, these configurations are labeled $B$ for bellmouth, and $\mathbf{S}$ for the S-contoured hub. Configuration $B$ has lower acceleration near the front portion of the vane than configuration $S$ for the same pressure ratio. The meridional view only indicates a part of the acceleration, since the flow is turned from axial to an average of about 70 degrees.

Figure $1 \mathrm{~b}$ shows the vane profile with the hub configuration $B$. The vane trailing edge angle varies from hub to tip. The highest amount of turning occurs near mid-span, and the lowest amount of turning at the hub endwall. This figure also shows the C-type grids used for the analysis. C-type grids were chosen in order to obtain good resolution of the flow field, and hence heat transfer, in the leading edge region.

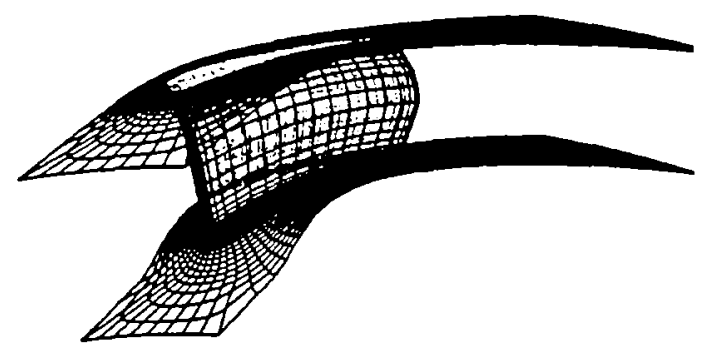

Fig. 1b Typical grid used for analysis. Grid generation. For the test Reynolds numbers the desired near-wall spacing was $1 \times 10^{-5}$ of $c_{x}$ to obtain maximum values of $y_{1}^{+}$of approximately one, which are needed to insure accurate results. Two approaches were taken for grid generation. A common grid was used for both flow analysis codes. Best results were obtained using an embedded grid with a non-matching condition along the cut line. A program, TCGRID, developed by Chima(1990), was initially used to obtain the grids used in the finite difference analysis. This program generates a series of two-dimensional fully elliptical grids in the blade-to-blade plane based on Sorenson's(1980) grid generation procedure. These grids, typically seven in number, are then stacked and interpolated to give a grid for each value of the spanwise index. For a $177 \times 49 \times 65$ grid, the seven blade-to-blade grids are interpolated to give 65 blade-to-blade plane grids. For a three-dimensional grid, the grid control parameters should be the same for each blade-to-blade section. Satisfactory three-dimensional grids with the desired nearwall spacing were not obtained using recommended orthogonality constraint parameter values. Relaxing the parameters gave unrealistic flow solutions, probably due to excessive grid stretching.

The approach finally taken for the finite difference analysis was to use the grid generation code developed for the finite volume flow analysis code, as described by Arnone et al.(1992). In this approach the blade-toblade grids are calculated in two steps. First a coarse grid, suitable for an Euler analysis, is generated using Sorenson's(1980) technique. A grid with the desired near-wall spacing is then embedded within the coarse blade-to-blade grid. The resulting blade-to-blade grids are then stacked to yield the three-dimensional grid. Typically, the degree of orthogonality at the wall is less for an embedded grid, than for a fully elliptical grid. For turbine blade grids, the degree of orthogonality is significantly improved if the constraint of matching grid lines along the cut line emanating from the trailing edge stagnation point to the downstream boundary is removed. In contrast to the two-dimensional results presented by 
Boyle and Ameri(1994), it was found that the convergence of the three-dimensional finite difference code, RVC3D, was significantly improved by not imposing a matching condition along the cut line. The finite volume analysis, TRAF3D, of Arnone et al.(1992) was developed to use grids which did not require a matching condition along the cut line.

For each configuration the grid size was $177 \times 49 \times$ 65 . There were 56 increments on the pressure side of the cut line in the wake region. There were 32 increments along the pressure side of the blade, and 64 increments along the suction side. There were 24 increments on the suction side of the wake region cut line.

Surface Pressures. Figure 2 shows a comparison of the predicted and experimental isentropic Mach numbers, as determined from the static to total pressure ratio, for both configurations. Even though the passage geometry is complex, there is little spanwise variation in either the predicted or measured surface pressures. The computations are consistent with the experimental data in predicting the spanwise variation in pressures. These results were obtained using the TRAF3D code, and predictions using the RVC3D code were nearly identical. Both CFD codes require the specification of either a uniform or average hub exit boundary pressure. Arts et al.(1990) have shown, for a similar vane, that when the exit Mach number exceeds unity, there was a considerable pitchwise variation in the midspan static pressure. At 0.42 chords behind the vane the maximum-tominimum variation in static pressure was $11 \%$ of the dynamic pressure at a Mach number of 0.85 , and increased to $23 \%$ at a Mach number of 1.1. The results shown in figure 2 are for a hub exit Mach number of 1.2. The blade surface pressure distribution was sensitive to the specified exit pressure. The tip exit pressure corresponded to an isentropic Mach number near unity, and had significantly less pitchwise variation than the hub exit pressure. Since only a few pressures were available to determine the appropriate exit boundary condition, the tip exit pressure was used. In the analysis, the hub exit pressure was adjusted so that the tip exit pressure matched the experimental value.

Figures 3 and 4 compare predicted and experimental hub and tip endwall isentropic Mach numbers for both configurations. Predictions were the same using either analysis, and the agreement with the data is good. Measurements, using approximately 53 taps per surface, extended from $0.06 c_{x}$ upstream of the leading edge to $0.13 c_{x}$ downstream of the trailing edge. The predictions, which extend beyond the blade region, show the pitchwise variation in isentropic Mach number to be greater for the hub than for the tip.
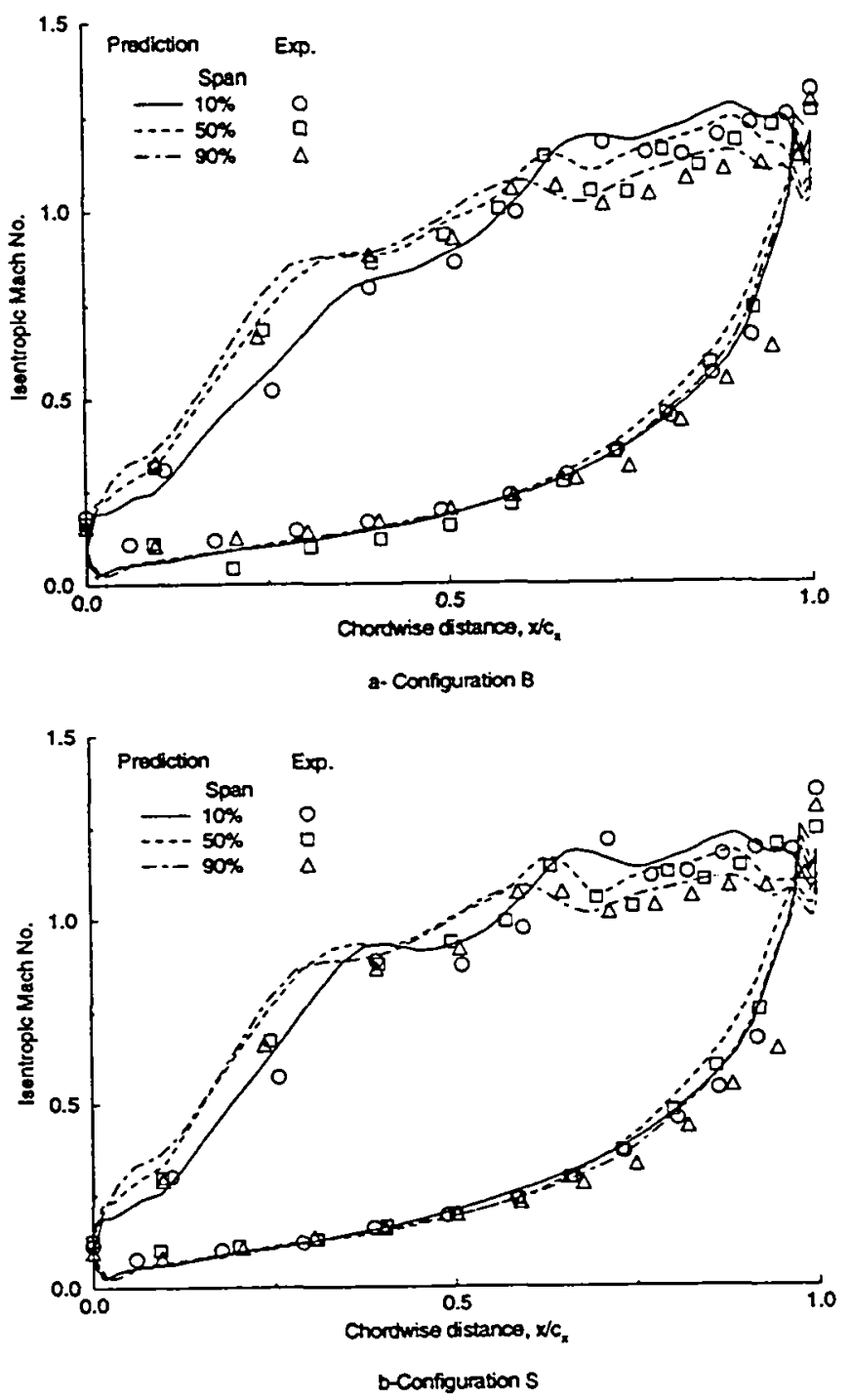

Fig. 2 Vane surface pressure distribution.

Heat Transfer Comparisons. In this section predicted and measured vane and endwall heat transfer are compared. Predictions of surface pressure distributions were nearly identical using either flow analysis. However, predictions of surface heat transfer were different between the two analyses. Since the analyses incorporated different turbulence models, these differences could be due to either the analyses themselves, or in the turbulence models. It will be shown that the primary difference in the heat transfer results between the two analyses is due to the choice of turbulence model.

Comparisons of the predicted and measured vane surface Nusselt numbers are given in figure 5 using the 

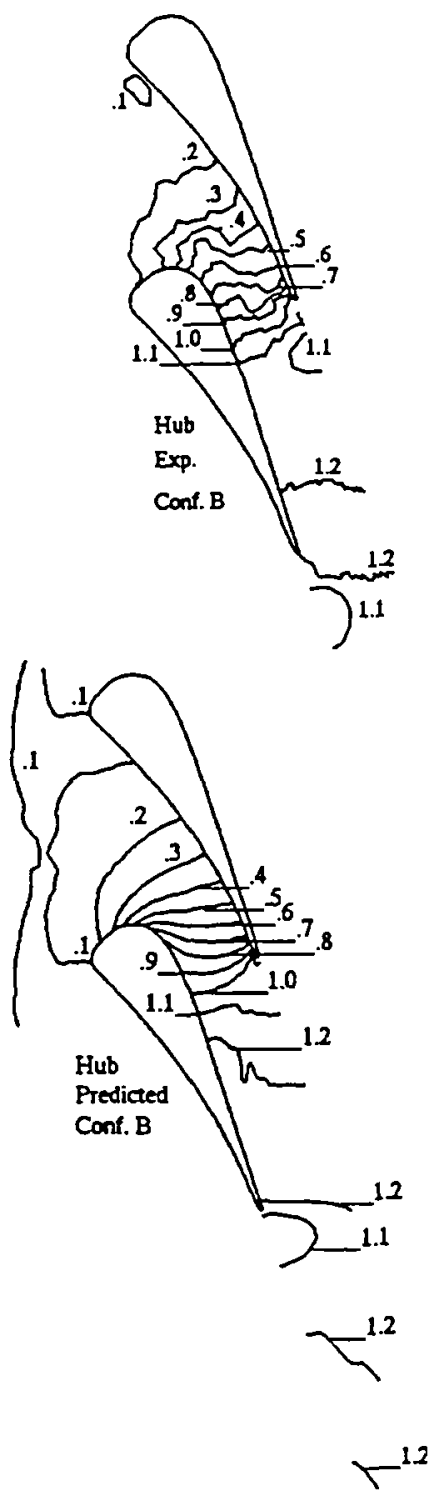

Fig. 3a $M_{1 \mathrm{~S}}$ for configuration B hub.

Baldwin-Lomax turbulence model, and in figure 6 using Chima's turbulence model. Except for the suction surface transition region, there is little spanwise variation in the experimental Nusselt number. Even though the variation is not large, the results show that the midspan region of the suction and pressure surfaces have higher heat transfer than near either endwall. The peak suction surface heat transfer occurs at transition, and is highest for the data at $50 \%$ and $98 \%$ of span. The leading edge region heat transfer is relatively low compared to the average suction surface value. This results from the endwall convergence, which gives lower inlet velocities compared with constant radius endwalls.
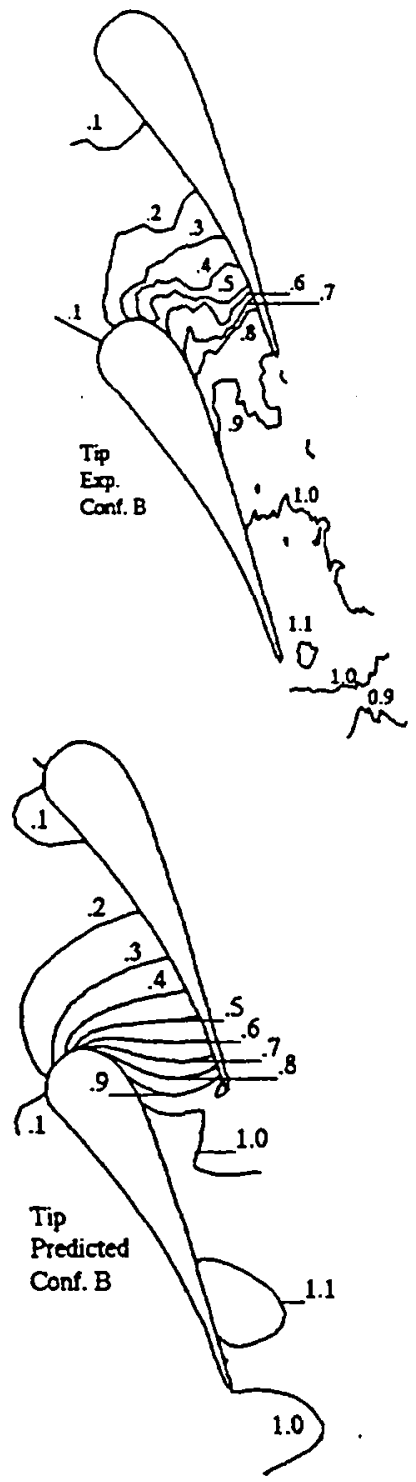

Fig. 3b $M_{\mathrm{IS}}$ for configuration B tip.

The TRAF3D analysis agrees well with the data at the leading edge, $s / c_{x}=0$, for both configurations. However, this analysis overpredicts the pressure surface heat transfer prior to transition, which occurs at the location of minimum heat transfer. The RVC3D analysis underpredicts the midspan heat transfer at the leading edge, but is in good agreement with the pressure surface data prior to transition. The difference is a consequence of the TRAF3D prediction incorporating the Smith and Kuethe(1966) model to account for the effects of freestream turbulence on laminar heat transfer, while the RVC3D prediction did not include a model for this effect. Without this model both analyses gave the same leading edge heat transfer rates. 


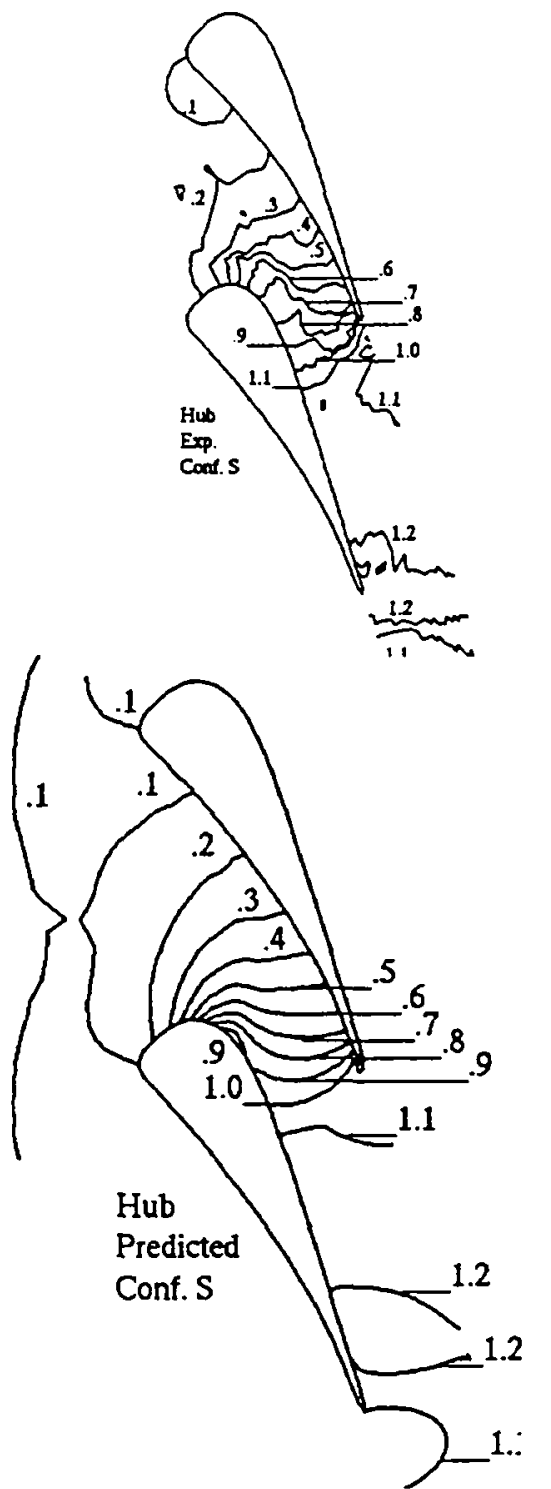

Fig. 4a $M_{\mathrm{IS}}$ for configuration $\mathrm{S}$ hub.

The predicted suction surface transition occurs downstream of the experimental location. This is a consequence of the way Mayle's(1991) transition model was implemented. In this model the start of transition occurs when $R e_{\theta}=400 T u^{-5 / 8}$. The measured upstream $T u$ was $6.5 \%$. It was assumed that the fluctuations remained constant to determine the local $T u$ for the transition criterion. The upstream Mach number was 0.14 , so that the local calculated $T u$ at transition was approximately $1 \%$. If the turbulence intensity is held constant, the predicted suction surface transition location occurs closer to the leading edge than is shown by the data. The results of Young et al.(1992), lead to the expectation that the primary effect of high freestream

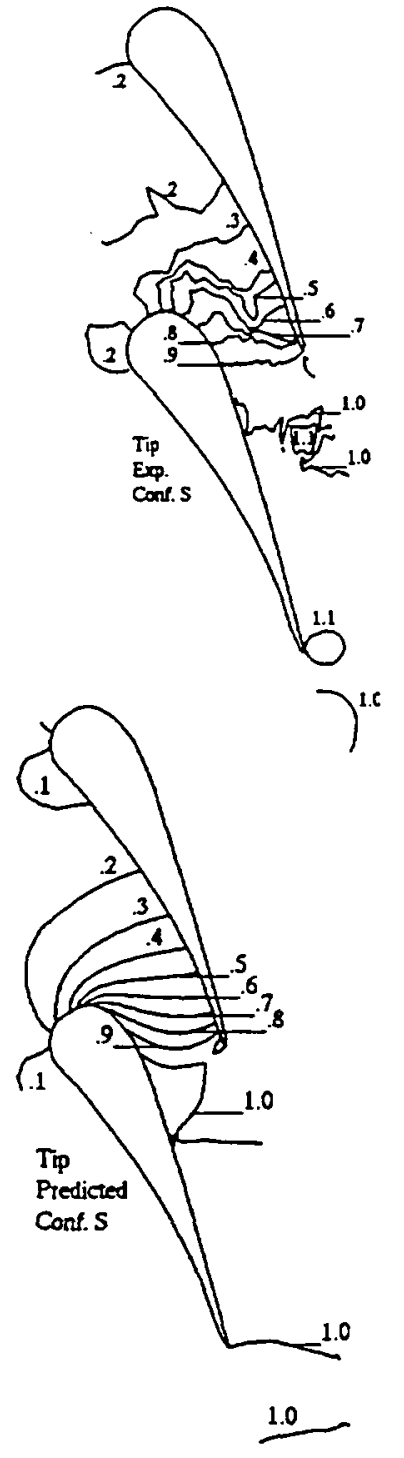

Fig. $4 b M_{I S}$ for configuration $S$ tip.

$T u$ was to cause early transition. They showed that the effects of high freestream $T u$ are at a minimum when either $R e_{\theta}$, or the length scale to boundary layer thickness ratio is large. $R e_{\theta}$ is large on the endwalls, and the boundary layer thickness is small on the vane.

Both predictions show the correct spanwise variation in suction surface heat transfer after transition, where the highest values are at midspan and the lowest value are at $2 \%$ of the span. However, both analyses overpredict the amount of spanwise variation. This may not be due to defects in the turbulence model, since, as is shown in a subsequent figure, the vane suction surface heat transfer changes very rapidly near the end wall. The measurements may have averaged the heat transfer rates for a region close to the endwall. 

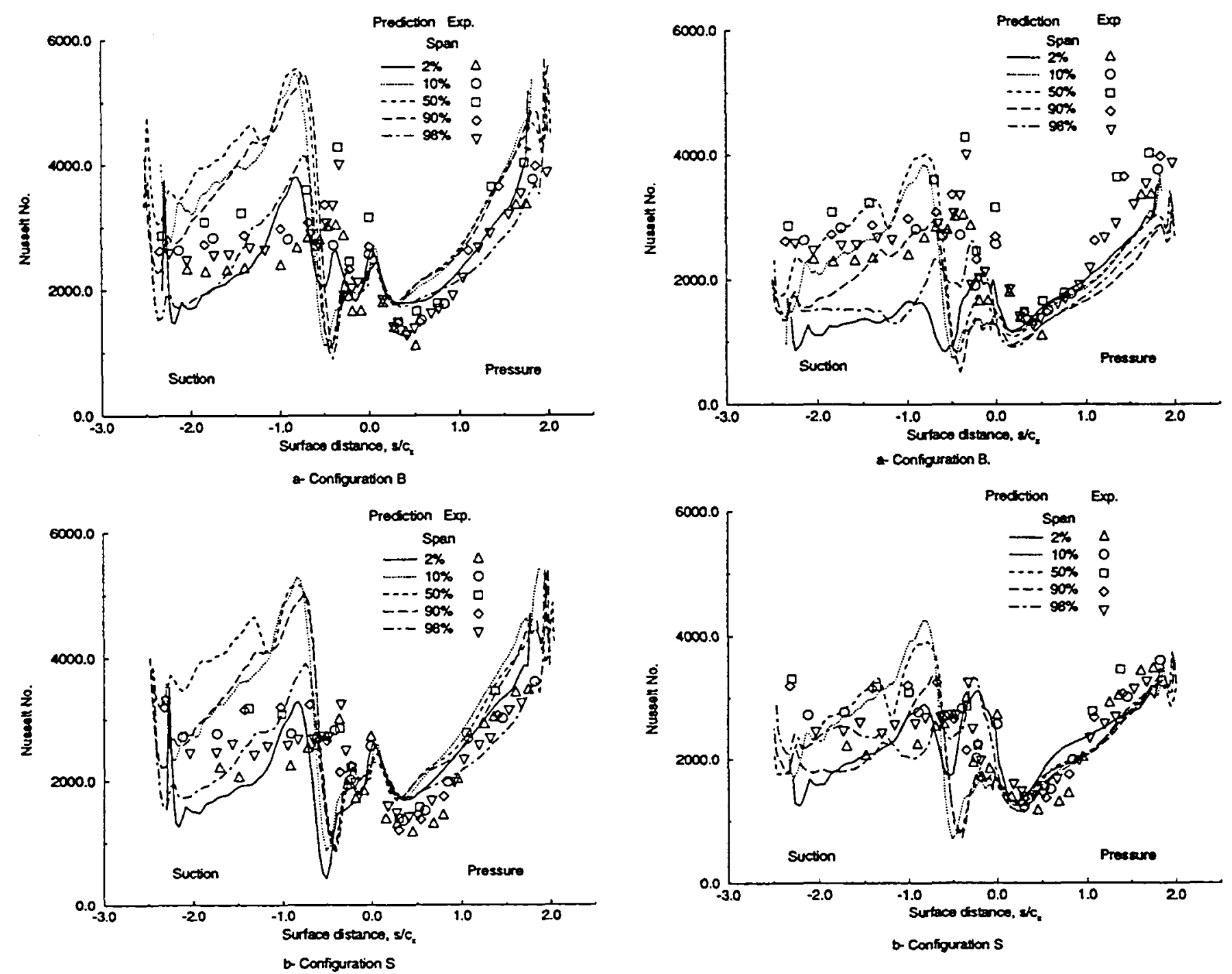

Fig. 5 Heat Transfer,Baldwin-Lomax(TRAF3D) model.

The two predictions differ in the calculated heat transfer in the near wall region at 2 and $98 \%$ of span. This is especially evident near the leading edge for configuration S. The RVC3D prediction shows much higher heat transfer levels near the endwalls compared to midspan. The TRAF3D prediction shows smaller spanwise variation in this region. This is due to different assumptions made in the respective analyses. In the RVC3D code the eddy viscosity at a point is calculated from: $\mu_{t}=\sqrt{\left(\mu_{t}\right)_{1}{ }^{2}+\left(\mu_{t}\right)_{2}{ }^{2}} \cdot\left(\mu_{t}\right)_{1}$ is found by considering only the effect of the blade surface, and $\left(\mu_{t}\right)_{2}$ is found by considering only the effect of the endwall surface. Also, the length scale used for both values of $\mu_{t}$ is the Buleev length scale, which can be approximated as the minimum distance to either surface. The

Fig. 6 Heat Transfer,Chima's(RVC3D) model.

TRAF3D code, however, weighs the individual contributions to the eddy viscosity. $\mu_{t}=R\left(\mu_{t}\right)_{1}+\left(\mu_{t}\right)_{2}(1-$ $R)$. And, $R=d_{2}^{2} /\left(d_{2}^{2}+d_{1}^{2}\right)$. For each value of $\mu_{t}$ the length scale is the normal distance to the appropriate wall. In the corner region the eddy viscosity in the RVC3D code can be nearly $40 \%$ greater than the maximum value from one surface. In this same region the TRAF3D assumption limits the value to the greater of the two values. Consequently, the RVC3D assumption gives greater eddy viscosity in the corner region, even for the same turbulence model assumptions. The results in figures 5 and 6 , show that the RVC3D code assumption regarding the eddy viscosity is in better agreement with the experimental data.

Predictions were also made using the RVC3D code with the Cebeci-Smith turbulence model. Except for 

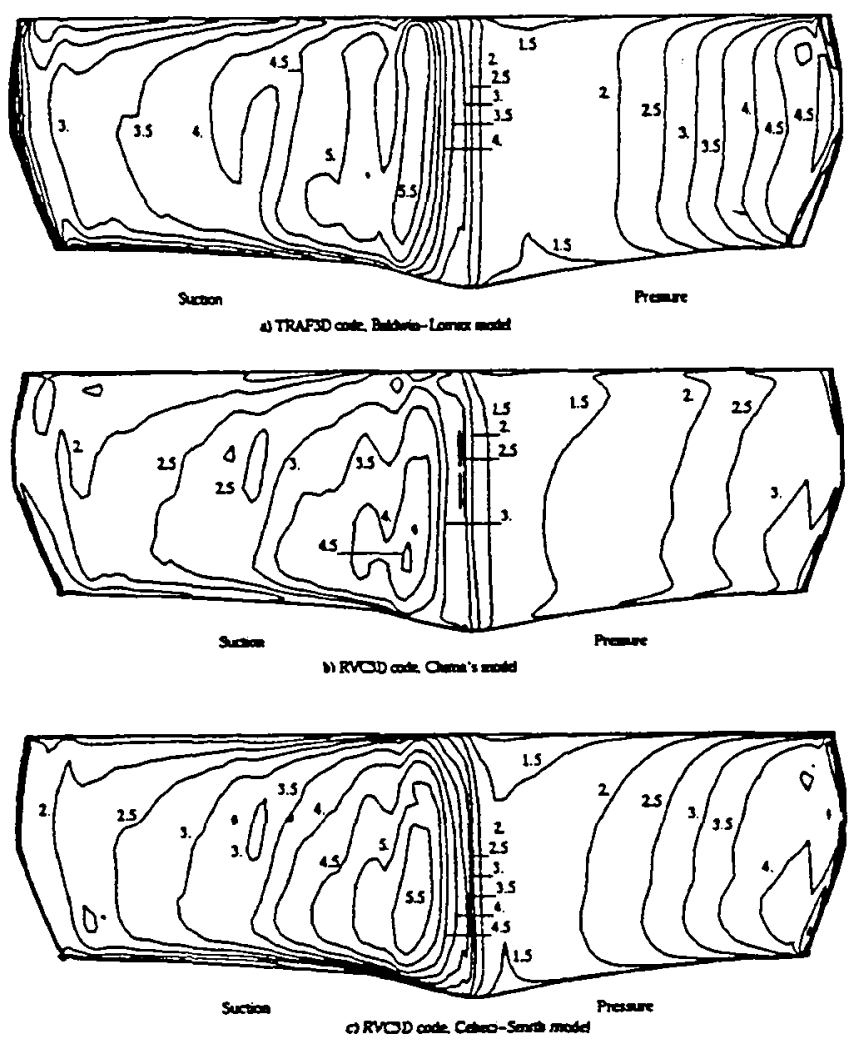

the differences noted due to the implementation of the models, the Cebeci-Smith results were similar to the Baldwin-Lomax results shown in figure 5 .

Other differences in predicted heat transfer between the two turbulence models can be highlighted if transition effects are absent. Figure 7 shows a contour plot of $\mathrm{Nu}$ as a function of span and surface distance for configuration B, and assuming fully turbulent flow. Similar results were obtained for configuration $S$. This figure shows comparisons of predictions for five different cases, and illustrates the effect of varying the turbulence model using the two flow solvers. The horizontal axis is the surface distance along the suction and pressure surfaces of the vane. Because of the endwall contour, the leading edge is at the location of maximum span. Part a of the figure shows $N u$ for the TRAF3D code with the Baldwin-Lomax turbulence model. Parts b, c, and d show RVC3D code results with Chima's turbulence model, the Cebeci-Smith turbulence model, and the Baldwin Lomax turbulence model respectively. These three figures show the surface heat transfer for different turbulence model using the same flow solver and grid. The Cebeci-Smith model gives the highest vane heat transfer. The other two models give similar surface heat transfer. Comparing the heat transfer in parts $a$ and $d$ shows differences in heat transfer between the two flow solvers for the same turbulence model.
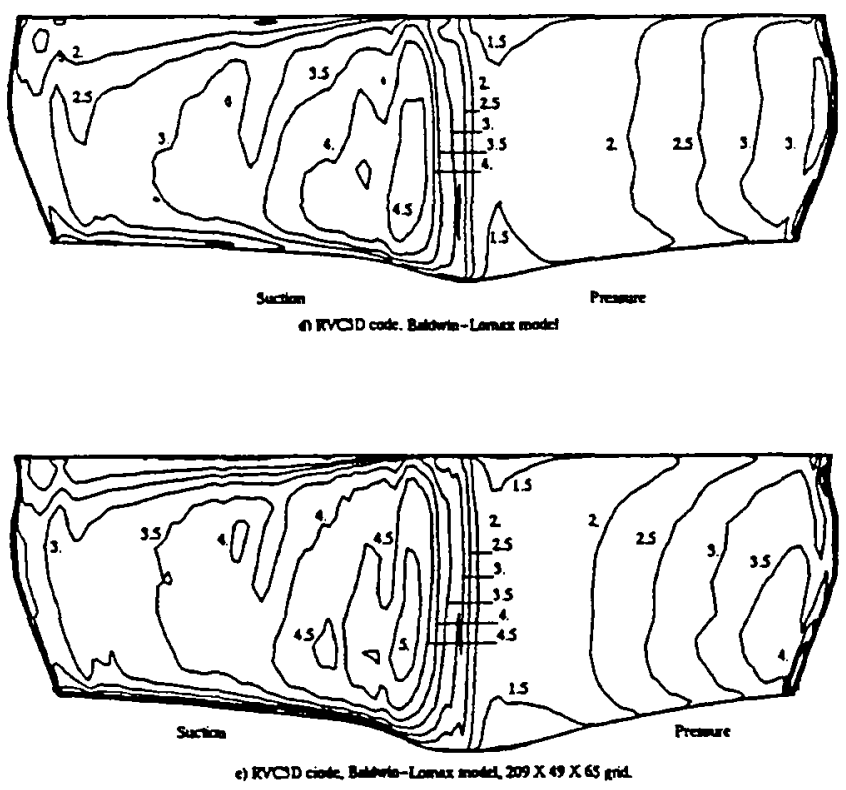

Fig. $7 N u \times 10^{-3}$ for configuration $B$, fully turbulent assumption

The differences are on the same order as the differences among the three turbulence models. The differences are not due to either differences in the implementation of the turbulence model, or to inherent differences between the codes. If the $\mu_{i}$ from the converged TRAF3D case was used in the RVC3D code, and the $\mu_{t}$ calculation bypassed, the heat transfer was the same as in part d. The differences are due to the RVC3D code exhibiting a greater grid sensitivity than the TRAF3D code. Part e shows the vane heat transfer using a finer grid in the streamwise direction. Overall, this grid was about $20 \%$ larger, but had a $50 \%$ increase in the number of grid lines, (from 32 to 48 increments), along the pressure surface. Sixteen increments were also added to the suction surface. The results in part $e$ are in closer agreement with the part a results. When the TRAF3D analysis was run with the finer grid, the vane heat transfer was nearly identical to that shown in part $a$.

In an effort to understand the differences among the results the manner in which the models were implemented was investigated. The TRAF3D code uses Sutherland's Law to determine the variation of viscosity, and hence conductivity, with temperature. The RVC3D code uses a power law for this variation. Using the power law variation in the TRAF3D code did not change the predicted heat transfer.

The Baldwin-Lomax model was applied everywhere in the flow field. In the RVC3D code a distinction was made, based on an input variable, between a "near wall" region and the entire flow field. For a $j$ index greater 
than a $j$ EDGE, the turbulent eddy viscosity was set to the outer region value, independent of where the crossover between the inner and outer regions occurred. Extending $j_{\text {EDGE }}$ to the grid size index resulted in no significant change in the predicted heat transfer. Only when the turbulent eddy viscosity was suppressed completely for $j$ values greater than $j_{\text {EDGE }}$ was the heat transfer reduced by 10 to $15 \%$.

Both codes calculate the length scale in the same manner. For the vane or endwall the length scale is calculated as the normal distance from the grid line(RVC3D) or cell center(TRAF3D) to the appropriate surface. Taking the distance along the grid line for the length scale overestimates the length scale, and resulted in vane heat transfer rates up to $50 \%$ higher for both codes. This difference is due to the grids having significant degrees of non-orthogonality. Endwall heat transfer results were also sensitive to the approach taken to calculate the length scale.

Figures 8 and 9 compare predictions of endwall heat transfer with experimental data for both analyses for configurations $B$ and $S$ respectively. The experimental data extended from $0.11 c_{x}$ upstream of the leading edge to $0.11 c_{x}$ beyond the vane trailing edge. There were between 28 and 39 heat transfer measurements on each endwall. Upstream of the blade leading edge there was little variation in endwall heat transfer. The inlet $N u$ was calculated to be 1245 . While the choice of the transition location noticeably affected the vane surface heat transfer, the location of transition on the vane had no noticeable affect on endwall heat transfer. Based on the measured inlet boundary layer thickness, the inlet endwall boundary layers was taken as fully turbulent.

The predictions shown in these figures are for a $177 \times 49 \times 65$ grid. There was no significant difference in the predictions when a $209 \times 49 \times 65$ grid, or a $177 \times$ $49 \times 89$ grid was used.

Comparing figures $8 a$ and $9 a$ shows that configuration B had a somewhat lower hub heat transfer in the leading edge region, and a slightly higher heat transfer in the throat region. The predictions with any of the turbulence models do not show any significant differences between the two configurations in the leading edge region. This is somewhat surprising, since, as is shown in figure 1, this is the region where there is a difference in the hub contour. In the throat region the BaldwinLomax model predicts the same hub heat transfer for either configuration, with a peak value that closely agrees with the measurements. Chima's turbulence model underpredicts the peak heat transfer in the throat region, and is generally lower than the experimental data for most of the passage. The Cebeci-Smith model over-
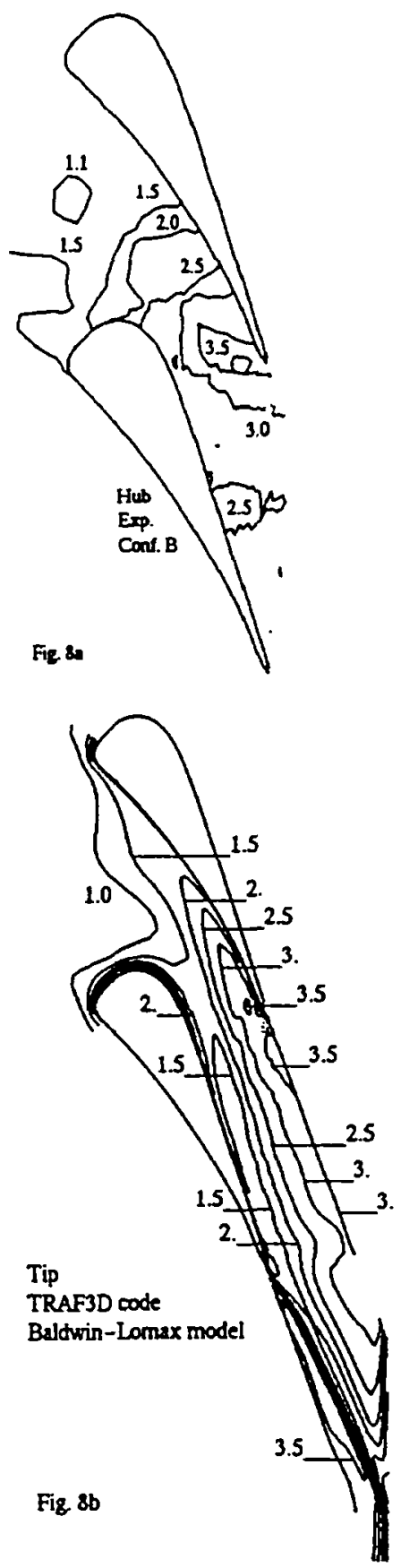

predicts the peak heat transfer in the throat region, but generally agrees well with the experimental data.

In the tip region the experimental data are, as expected, relatively the same for both configurations. Again, there is a slightly higher throat region heat transfer for configuration $B$. The tip data show a region of high heat transfer at the top of the suction surface for configuration B, but not for configuration S. 

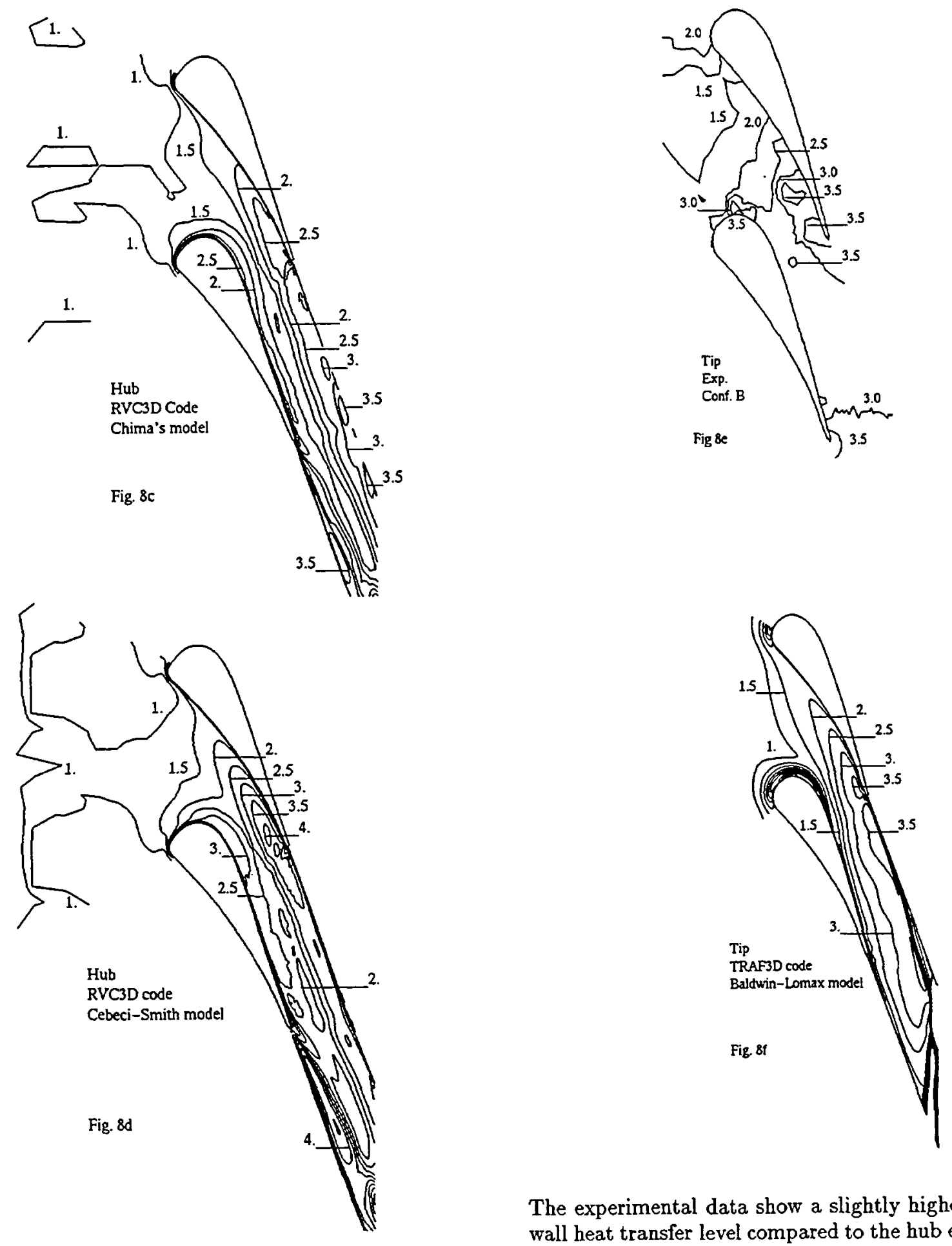

The predictions show the high heat transfer to be confined to only a small region of the tip endwall. Both the hub and tip predictions show the same relative agreement with the data for either hub configuration.

The experimental data show a slightly higher tip endwall heat transfer level compared to the hub endwall for both configurations. The predictions also show higher heat transfer on the tip endwall for a small region near the suction surface, close to the peak of the blade. This behavior is consistent with the experimental vane data shown in figure 5 . At this vane surface region, 

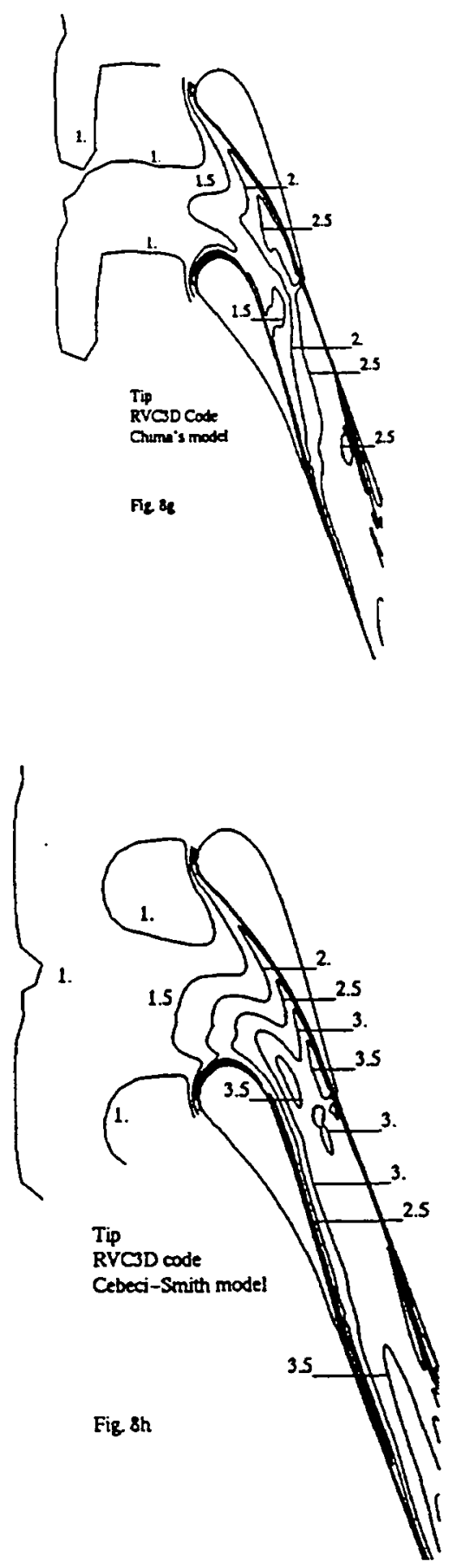

Fig. $8 \mathrm{Nu} \times 10^{-3}$ for configuration B.

the data, especially for configuration $B$, show higher heat transfer at $98 \%$ of span than at $2 \%$ of span. Along the suction surface region for either configuration the Baldwin-Lomax results show lower heat transfer than the other predictions. The other two predictions agree
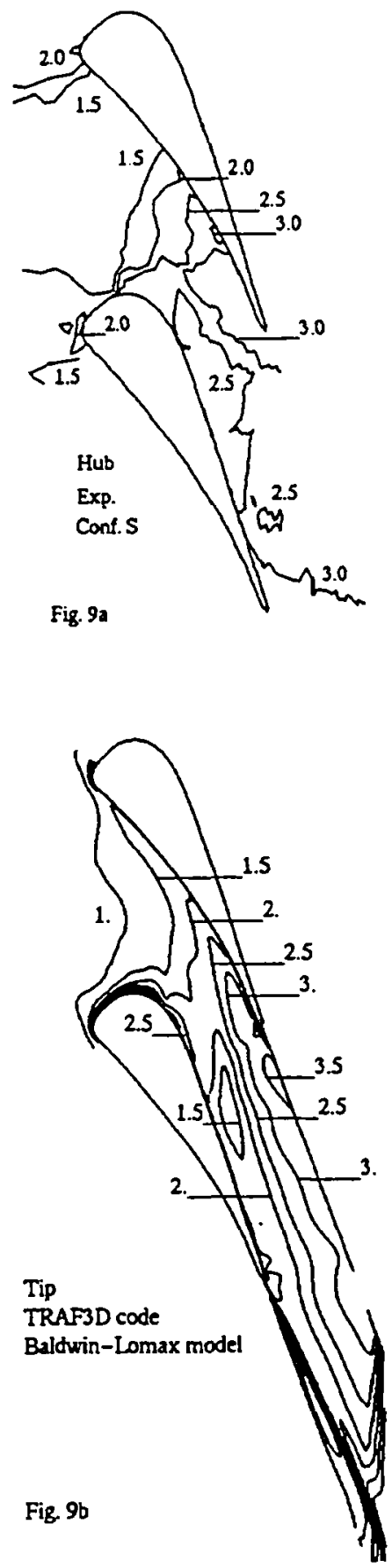

better with the data in this region. The better agrement is partly is due to differences in the turbulence models, and partly due to the way in which $\mu_{t}$ is calculated. The summation used in the RVC3D code results in greater eddy viscosity in the corner region compared with approach taken in the TRAF3D code. Using the 

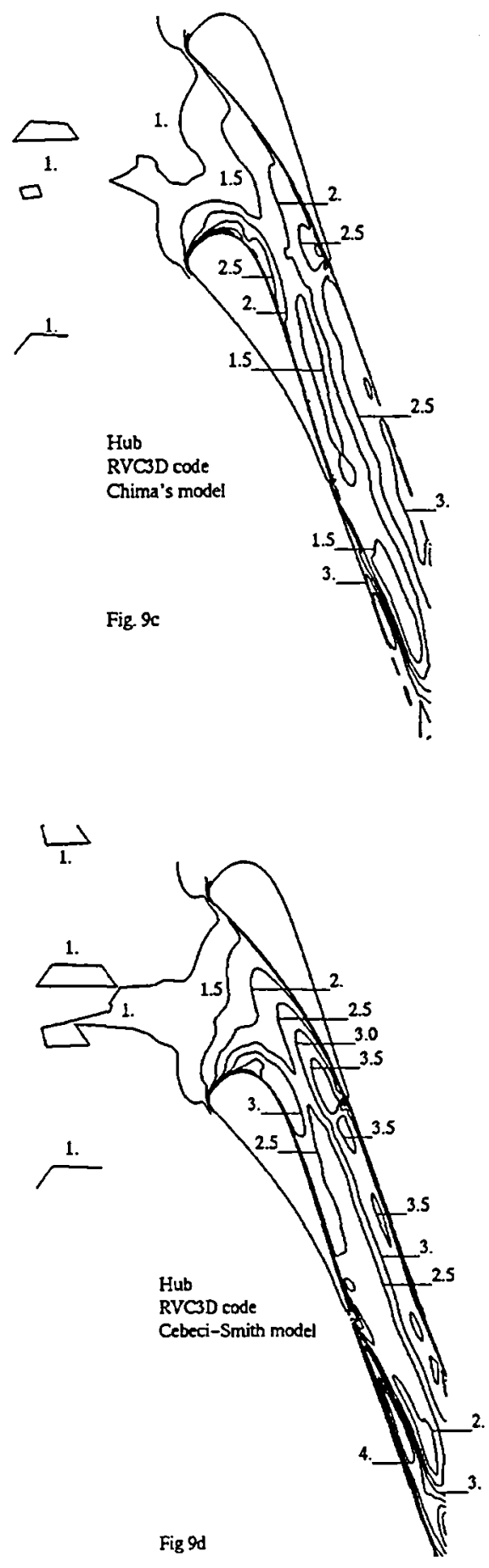

TRAF3D approach in the RVC3D code resulted in lower endwall heat transfer close to the suction surface.

In an overall sense the Cebeci-Smith turbulence model tends to overpredict the endwall heat transfer, but to be in reasonably good agreement with the data. The Baldwin-Lomax results underpredict the heat
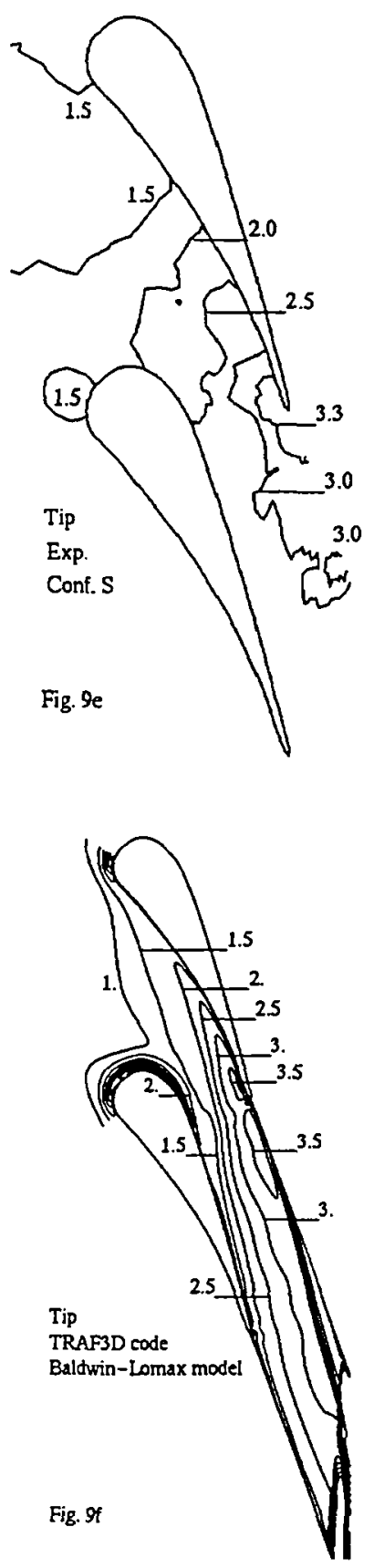

transfer in the region near the suction surface, but agree reasonably well with the data elsewhere. Chima's model underpredicts the heat transfer. This is especially true for the maximum heat transfer in the throat region.

Total Pressure Distribution. Figure 10 compares the total pressure distributions at 0.20 axial chords downstream of the trailing edge. Both computed results overpredict the depth of the wake, 


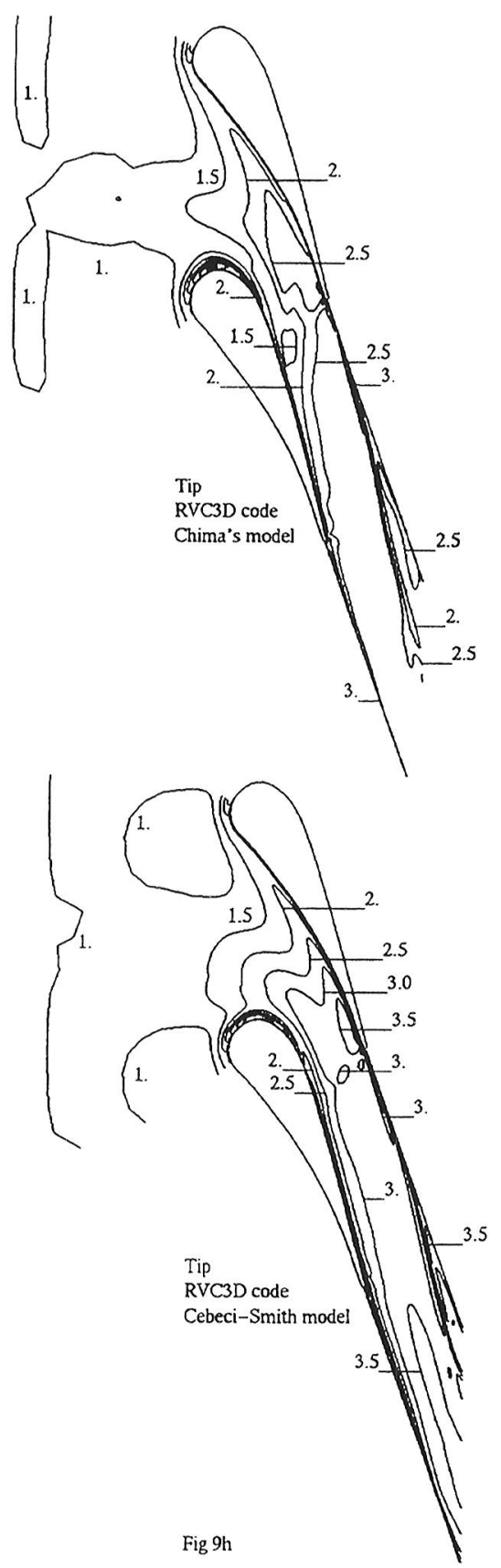

Fig. $9 \mathrm{Nu} \times 10^{-3}$ for configuration S.

but correctly predict the spanwise variation in the wake characteristics. The wake is thickest, and has moved further in the tangential direction, near midspan. Near midspan the minimum experimental total pressure ratio was 0.84 . The RVC3D results were very similar for either turbulence model, and had a minimum total pressure ratio of 0.67 . The TRAF3D results had a minimum total pressure ratio 0.74 . The spanwise variation

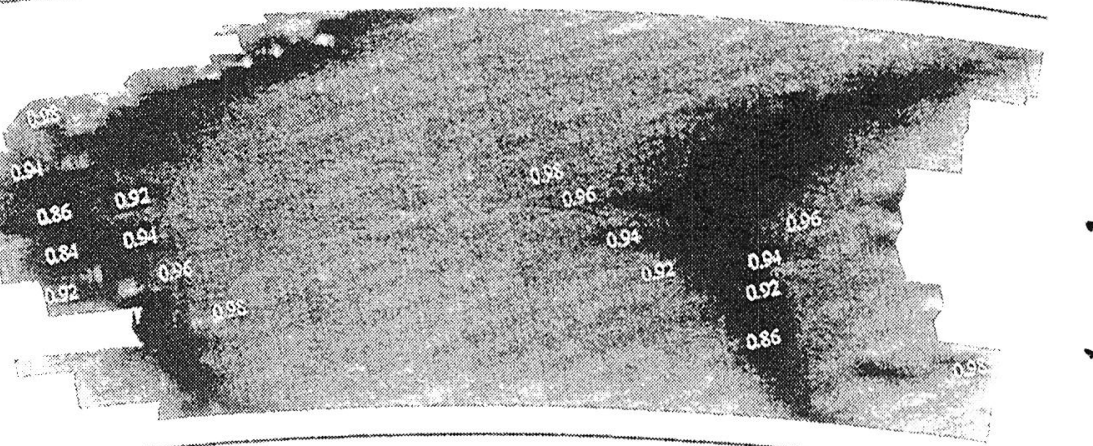

a) Exp. data of Chana

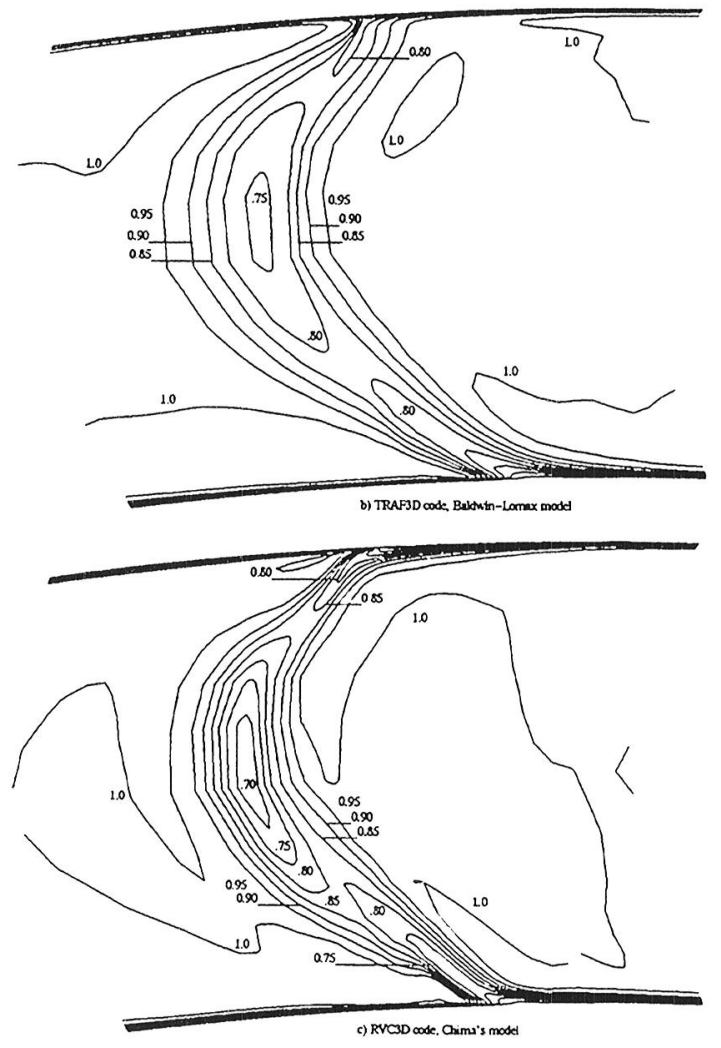

Fig. 10 Total pressures $0.2 c_{x}$ behind vane. in the location of the minimum pressure shows that the parabolic variation in flow turning with span is well predicted. Also, both predictions are in agreement with the experimental data in that the wake is widest near midspan. The overprediction of the depth of the wake is consistent with the results shown by Boyle and Ameri(1994) in a two-dimensional analysis of the effects of grid topology on the aerodynamic and heat transfer characteristics of a high turning transonic vane. The tendency to overpredict the wake depth is not confined to the CFD methodologies used for this work. Results of the ASME compressor rotor test case for Rotor 37(Strazisar,1994) showed that many analyses overpredicted the wake depth for the transonic compressor rotor. 


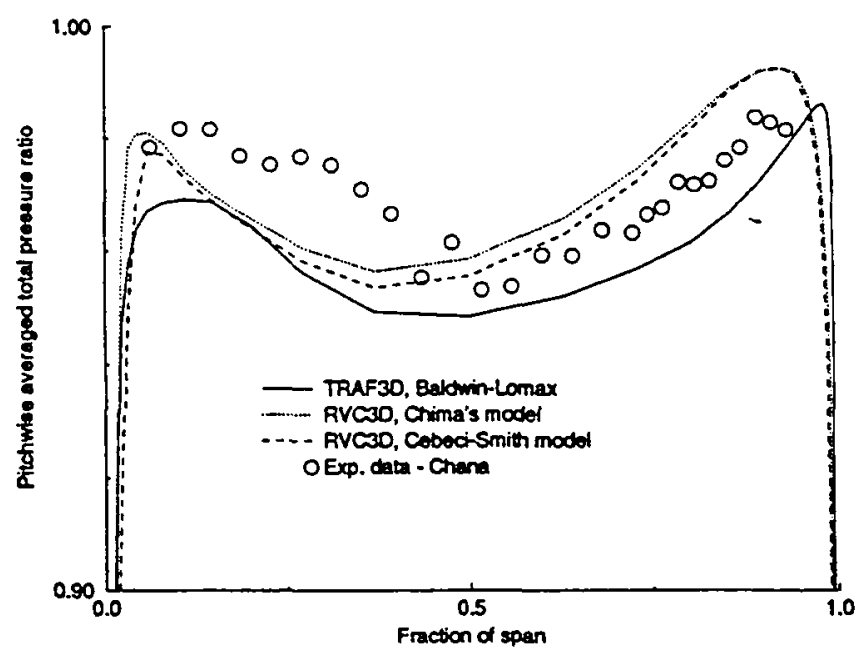

Fig. 11 Spanwise total pressure variation.

The analyses predict a wake that is both too narrow and too deep. These effects compensate to some degree, and the pitchwise averaged total pressure downstream of the rotor is reasonably well predicted. This is illustrated in figure 11 where the spanwise variation in pitchwise averaged total pressure is shown. Both the experimental data and predictions were area averaged in the blade-to-blade direction to obtain these results. The experimental data extend from 6 to $94 \%$ of span, and show very low loss regions near the endwalls. The maximum experimental loss occurs near midspan. Both predictions give too large a loss between the hub and midspan. The hub region is one of minimumstatic pressure, so that in the region between hub and midspan, overall loss is sensitive to shock losses.

\section{CONCLUDING REMARKS}

Heat transfer predictions were made using a finite difference(RVC3D) and a finite volume(TRAF3D) computer code for two vane geometries typical of actual engine applications. The test conditions of $M_{2}=1.2$, and $R e_{2}=5.6 \times 10^{6}$ provided a severe test of the codes computational capability. Convergence was heavily influence by the choice of grid topology. The grid generation procedure described by Arnone et al.(1992) resulted in grids which gave satisfactory results for both codes. These grids were generated by embedding a near-wall grid. Primarily because of the required near wall spacing of $1 \times 10^{-5} c_{x}$, it was found that using a non-matching condition along the cut line was highly desirable in terms of obtaining converged solutions.

Solutions obtained with both codes converged in approximately the same number of CPU hours. Typically, the grids used were 560,000 points, and the solution was obtained in two hours on a Cray C90 computer.
As expected the surface pressure distribution converged more rapidly than the surface heat transfer. Since the solution was stopped only after the heat transfer distributions were seen not to change over a large number of iterations, the actual convergence for either code may have taken somewhat less than two hours.

Both computational analyses correctly predicted the spanwise variation in vane surface pressures, and the endwall static pressures for both experimental configurations. Best agreement with the data was achieved when the predicted exit static pressure was matched to the measured tip value. There was a larger pitchwise static pressure variation at the hub than at the tip. To minimize uncertainty, measured tip, rather than hub, values should be used for exit boundary pressures.

Blade heat transfer predictions agreed reasonably well with the data for the pressure side of either vane for all turbulence model assumptions. On the suction surface of the blade Chima's turbulence model produced results that agreed best with the data. This was independent of the choice of the transition model. The location of transition on the suction surface using Mayle's model was bounded by the choice of local $T u$ used in the model. Assuming constant $T u$ resulted in early transition, and assuming the fluctuation constant resulted in transition too far aft on the vane suction surface.

Differences in predicted endwall heat transfer among the different turbulence models were greater than the differences in experimental heat transfer between the two configurations. The results with the Cebeci-Smith turbulence model were in reasonably good agreement with the data, but tended to overpredict the peak heat transfer. The approach taken in the RVC3D code to determine $\mu_{t}$ in the corner region gave better agreement with the data compared to the approach taken in the TRAF3D code. There were significant heat transfer variations using the different turbulence models. Therefore, cases with significant variations in Reynolds number should be examined to determine if the degree of agreement with the data remains the same. This would increase the level of confidence in whichever turbulence model is used for predictions.

Both computer analyses correctly predicted the spanwise variation in the wake behind the vane. Both analyses predicted too low of a value for the minimum total pressure in the wake region. This appeared to be due to underprediction of pitchwise mixing. The spanwise distribution of the pitchwise averaged total pressure was well predicted. The analyses and the data showed minimum total pressure loss close to both endwalls. 


\section{Acknowledgements}

Contributions to the resourcing of this work were made by the National Aeronautics and Space Administration and by the United Kingdom's Ministry of Defence and the Department of Trade and Industry.

\section{REFERENCES}

Ameri, A.A. and Arnone, A., 1992, "Navier-Stokes Heat Transfer Predictions Using Two-Equation Turbulent Closures," AIAA Paper AIAA-92-3067.

Ameri, A.A. and Arnone, A., 1994, "Prediction of Turbine Blade Passage Heat Transfer Using a Zero and a Two-Equation Turbulent Model, ASME Paper 94-GT-122.

Arnone, A, Liou, M.-S, and Povinelli, L. A., 1992, "NavierStokes Solution of Transonic Cascade Flows Using Non-Periodic C-Type Grids," AIAA Journal of Propulsion and Power, Vol. 8, No.2, pp $410-417$.

Arts, T., Lambert de Rouvroit, M., and Rutherford, A. W., 1990, "Aero-Thermal Investigation of a Highly Loaded Transonic Linear Turbine Guide Vane Cascade," von Karman Institute for Fluid Dynamics, Technical Sote 174.

Arts, T, and Heider, R., 1994, "Aerodynamic and Thermal Performance of a Three Dimensional Annular Transonic Nozzle Guide Vane. Part I: Experimental Investigation," AIAA Paper AIAA-94-2929.

Baldwin, B.S. and Lomax, H., 1978, "Thin- Layer Approxinnation and Algebraic Model for Separated Turbulent Flows," AIAA Paper AIAA-i8-257.

Blair, M. F., 1974, "An Experimental Study of Heat Transfer and Film Cooling in Large-Scale Turbine Endwalls," ASIIE Journal of Heat Transfer, Vol 96, pp.525-529.

Blair, M. F., 1994, "An Experimental Study of Heat Transfer in a Large-Scale Turbine Rotor Passage," ASME Journal of Turbomachinery, Vol 116, pp.1-13.

Boyle, R. J, and Russell, L. M., 1990, “An Experimental Determination of Stator Endwall Heat Transfer," ASME Journal of Turbomachinery, Vol 112, pp.547-558.

Boyle, R.J., and Giel, P.W., 1992, Three-Dimensional Navier-Stokes Heat Transfer Predictions for Turbine Blade Rows," ALAA paper AIAA-92-3068.

Boyle, R.J., and Ameri, A., 1994, "Grid Orthogonality Effects onPredicted Turbine Midspan Heat Transfer and Performance," ASHE paper 94-GT-123.

Chana, K.S., 1992, "Heat Transfer and Aerodynamics of a High Rim Speed Turbine Nozzle Guide Vane with Profiles End Walls," ASME paper 92-GT-243.

Cebeci, T., and Smith, A.M.O., 1974, "Analysis of Turbulent Boundary Layers, Acedemic Press, New York.

Chima, R.V., 1987, "Explicit Multigrid Algorithm for Quasi-Three-Dimensional Flows in Turbomachinery," AIAA Journal of Propulsion and Power, Vol. 3, No.5, pp 397-405.

Chima, R.V., and Yokota, J.W., 1988, Numerical Analysis of Three-Dimensional Viscous Internal Elorvs," AIAA paper 88-3522, (NASA TM-100878).
Chima, R.V., 1990, Private communication.

Chima, R.V., 1991, "Viscous Three-Dimensional Calculations of Transonic Fan Performance," AGARD Propulsion and Energetics Symposium on Computational Fluid Mechanics for Propulsion, San Antonio, Texas, May 2i-31.

Chima, R.V., Giel, P.W., and Boyle, R.J., 1993, "An Algebraic Turbulence Model for Three-Dimensional Viscous Flows," AAIA paper 93-0083, (NASA TM-105931).

Choi, D., and Knight, C.J., 1988, "Computations of 3D Viscous Linear Cascade Flows," AIAA Joumal Vol. 26, No. 12, pp 1477-1482.

Dunn, M. G., Kïm, J., Civinskas, K. C., and Boyle, R. J., 1994, "Time-Averaged Heat Transfer and Pressure Measurements and Comparison with Prediction for a Two-Stage Turbine," ASME Journal of Turbomachinery, Vol 116, pp.1422.

Graziani, R.A., Blair, M.F., Taylor, R.J., and Mayle, R.E., 1980, "An experimental Study of Endwall and Airfoil Surface Heat Transfer in a Large Scale Turbine Blade Cascade," Journal of Engineering for Power, Vol. 102, No. 2, pp. 1-11.

Hah, C., 1989, "Numerical Study of Three-Dimensional Flow and Heat Transfer Near the Endwall of a Turbine Blade Row, ${ }^{,}$AIAA paper 89-1689.

Harasagama, S.P., Wedlake, E.T., 1991, "Heat Transfer and Aerodynamics of a High Rim Speed Turbine Nozzle Guide Vane Tested in the RAE Isentropic Light Piston Cascade(ILPC)," ASME Journal of Turbomachinery, Vol. 113, Lio. 4, pp 384-391.

Heider, R. and Arts, T., 1994, "Aerodynamic and Thermal Performance of a Three Dimensional Annular Transonic Tozzle Guide Vane. Part II: Assessment of a 3D ilavier-Stokes Solver," AIA Paper ALAA-94-2930.

hays, W.M., Crawford, M.E., 1980, Convective Heat and Mass Transfer, McGraw-Hill Pub. Co.

Kingcombe, R.C., Harasagama, S.P., Leversuch, N.P., and Wedlake, E.T., 1989, “Aerodynamic and Heat Transfer Measurements on Blading for a High Rim-Speed Transonic Turbine, ${ }^{,}$ASME paper 89-GT-228.

Uayle, R.E., 1991, "The role of Laminar-Turbulent Transition in Gas Turbine Engines," ASWE Joumal of Turbomachinery. Vol. 113, pp 509-537.

Smith, M.C., and Kuethe, A.M., 1966, "Effects of Turbulence on Laminar Skin Friction and Heat Transfer," Physies of Fluids, Vol. 9, pp. $233 i-2344$.

Sorenson, R.L., 1980, “A Computer Program to Generate Two-Dimensional Grids About Airfoils and Other Shapes by the Use of Poisson's Equation,", NASA TM 81198.

Strazisar, A. J., 1994, Private communication.

York, R. E., Hylton, L.D., and Mihele, M. S., 1984, "Experimental Endwall Heat Transfer and Aerodynamics in a Linear Vane Cascade." ASME Journal of Engineering for Gas Turbines and Power, Vol 106, pp.159-16T.

Young, C.D, Han, J.C., Huang, Y., and River, R.B. 1992, "Influence of Jet-Grid Turbulence on Flat Plate Turbulent Boundary Layer Flow and Heat Transfer," ASME Joumal of Heat Transfer, Vol 96, pp.525-529. 


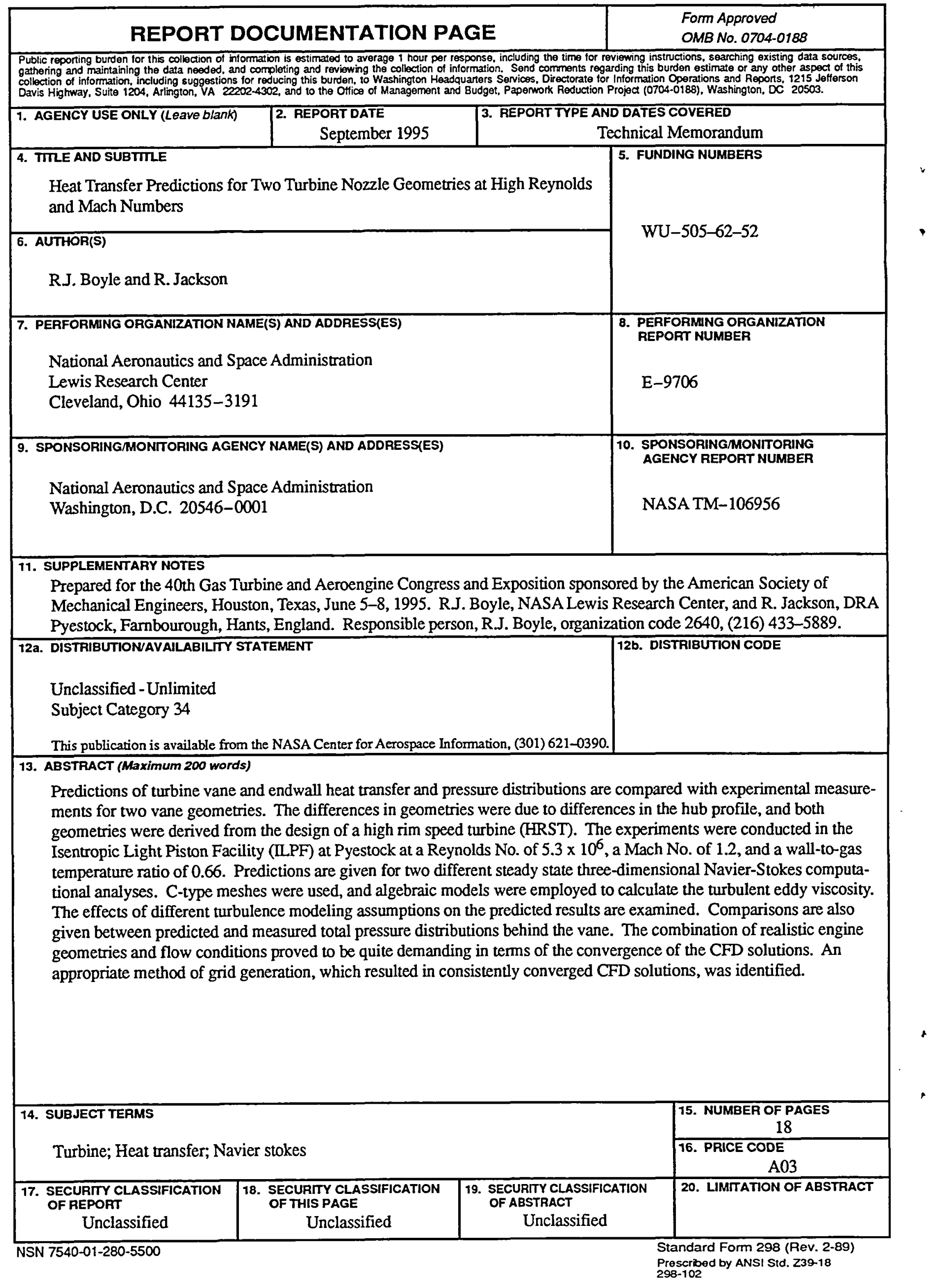


National Aeronautics and

Space Administration

Lewis Research Center

21000 Brookpark Rd.

Cleveland, $\mathrm{OH}$ 44135-3191

Officlal Business

Penalty for Private Use $\$ 300$

POSTMASTER: If Undeliverable - Do Not Return

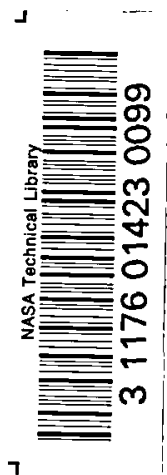

